\title{
COLETA E PREPARAÇÃO DE EXEMPLARES FÓSSEIS DE CAIUAJARA DOBRUSKII DO CRETÁCEO DA BACIA SEDIMENTAR DO PARANÁ
}

\section{COLLECT AND PREPARATION OF FOSSIL EXEMPLARYES OF CAIUAJARA DOBRUSKII OF CRETACEOUS IN SEDIMENTARY BASIN OF PARANA}

\author{
Marlon William NIZER ${ }^{1}$, Luiz Carlos WEINSCHÜTZ ${ }^{2}$ \\ ${ }^{1}$ Autor para contato. Graduado em Ciências Biológicas pela Universidade do Contestado \\ Campus Mafra. Avenida Presidente Nereu Ramos, 1071, bairro Jardim do Moinho, 89300- \\ 000, Mafra, SC, Brasil. Email: marlonnizer@gmail.com. \\ ${ }^{2}$ Professor orientador. Centro Paleontológico da Universidade do Contestado - CENPA- \\ LEO, Avenida Presidente Nereu Ramos, 1071, bairro Jardim do Moinho, 89300-000, Mafra, \\ SC, Brasil.Email: luizw@unc.br.
}

Data de recebimento: 09/06/2014

Data da aprovação: 30/10/2014

\section{RESUMO}

Esse artigo tem como finalidade demonstrar as técnicas de coleta e preparação utilizadas pela equipe do Centro Paleontológico (CENPALEO), da Universidade do Contestado, Mafra, SC, referentes à descoberta inédita de pterossauros do Cretáceo, na Bacia Sedimentar do Paraná, com financiamento do Programa Bolsa de Pesquisa do Artigo 170, da Secretaria de Estado da Educação de Santa Catarina. Até então não haviam sido encontrados fósseis de pterossauros na Bacia Sedimentar do Paraná. Essa descoberta é ainda mais curiosa, pois sugere-se que estes animais viviam em zona costeira e este sítio paleontológico encontra-se no meio do continente. O presente artigo descreve como foram feitas: a coleta de campo, a preparação em laboratório, as técnicas de preparação e identificação prévia do referido material. O trabalho teve como objetivo a instruir à iniciação científica, delimitando como deve proceder quanto à preparação de fósseis, utilizando materiais próprios, além das técnicas para coleta, embalagem e transporte adequado do material.

Palavras-chave: Pterossauros. Bacia do Paraná. Preparação.

\begin{abstract}
This journal was aimed Preparation and Identification of Specimens Fossils of pterosaurs Unpublished Cretaceous of the Paraná Sedimentary Basin, with funding from the Research Section 170, the Secretary of State of Santa Catarina. Still no fossils of pterosaurs have been found in the Paraná Sedimentary Basin. This finding is even more curious, because these animals lived in the coastal zone, and this paleontological site located in the middle of the continent. This article describes how was the collection of field, laboratory preparation, preparation techniques and preliminary identification of this material. The study aimed to instruct the academic scientific research, defining how to proceed as the preparation of fossils, using their own materials, and techniques for collecting, packaging and proper transportation of the material.
\end{abstract}

Keywords: Pterosaurs. Paraná Basin. Preparation. 


\section{Introdução}

Os pterossauros constituem uma ordem extinta de répteis, conhecida como Pterosauria. Estes arcossauros voadores, que foram contemporâneos dos dinossauros, constituem a primeira linhagem de vertebrados a conquistar o ambiente aéreo, mostrando elevada diversidade durante a Era Mesozoica (PINHEIRO, 2011). Apresentam grande adaptabilidade ao voo. Suas características ecológicas sugerem que habitassem vários ambientes, assim como as aves atuais. A ocorrência desses animais era conhecida no Brasil apenas na Chapada do Araripe, que ocorre nos estados do Ceará, Pernambuco e Piauí.

Em 2011, quando buscava material para fotografar e colocar em seu livro, o geólogo Paulo César Manzig se deparou com uma amostra de arenito proveniente do noroeste do estado do Paraná, e ela continha fósseis de pterossauro. "Era um pterossauro sim! Um possível filhote de pterossauro. Poderia haver algum erro de interpretação? Não, absolutamente não." (MANZIG; WEINSCHÜTZ, 2012, p. 226). Após uma busca, foi constatado que esse material provinha da cidade de Cruzeiro do Oeste, PR, onde o material havia sido coletado em 1975 e daí enviado para a Universidade Estadual de Ponta Grossa (UEPG), PR, para análise, não tendo, no entanto, recebido a atenção devida. A ocorrência de pterossauros na Bacia Sedimentar do Paraná causou certo impacto, pois ainda não havia sido constatada a existência desse tipo de fóssil na referida bacia.

\section{Coleta a Campo}

Desde a descoberta da ocorrência desses fósseis, a equipe do Centro Paleontológico (CENPALEO) da Universidade do Contestado (UnC), da cidade de Mafra, SC, faz coletas periodicamente nesse afloramento. A última fora realizada no mês de julho de 2014, quando materiais aí foram coletados, preparados e embalados de forma sistemática, a fim de facilitar o reconhecimento do local exato de coleta do material. Sem isso, seria impossível correlacionar os fósseis, para relacionar as partes a um mesmo indivíduo. Para que a coleta fosse feita de forma sistemática, o afloramento foi dividido em quadriculas com elásticos; para que, em caso de que algum acidente, a divisória não fosse rompida, cada quadricula recebeu uma identificação por meio de um número e uma letra. Para realizar a retirada do material foram utilizados equipamentos como marretas, talhadeiras, ponteiras, pincéis, alavancas, picaretas, pás e enxadas. Para a proteção dos membros da equipe foram usados equipamentos de proteção individual, como luvas e óculos de proteção, além de vestimenta adequada, como chapéu, calça de material resistente e calçado resistente.

Figura 1 - Equipe do CENPALEO trabalha no afloramento retirando fósseis. É possível observar que o afloramento está dividido em quadrantes, cada um recebendo um número e uma letra.

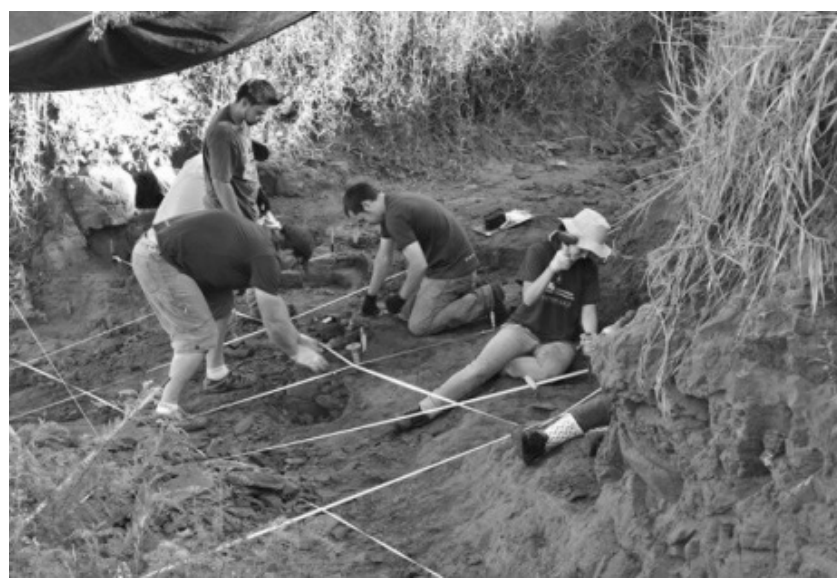

Fonte: Equipe CENPALEO.

Cada bloco retirado recebeu um número e foi relacionado à quadricula de onde fora extraído, sendo anotadas essas informações num guia de campo, um livro próprio para anotações sobre coletas a campo. Ainda foram feitas fotografias desses blocos com escalas métricas, uma foto em sua posição original e outra na posição invertida. Em caso de fragmentos retirados pertencentes ao mesmo bloco, foram anotados com a numeração do bloco mais um número de continuação.

Os blocos coletados foram devidamente embalados para que não sofressem danos no transporte. Para a embalagem foram utilizados papel higiênico, jornal, plástico bolha e fita crepe. Após serem embalados, escreveu-se a numeração do bloco, para possibilitar a identificação deste sem a necessidade de abrir a embalagem. 
Figura 2 - Exemplo de bloco coletado, com a numeração deste mais um número complementar, ainda com a escala métrica contendo a informação da quadra
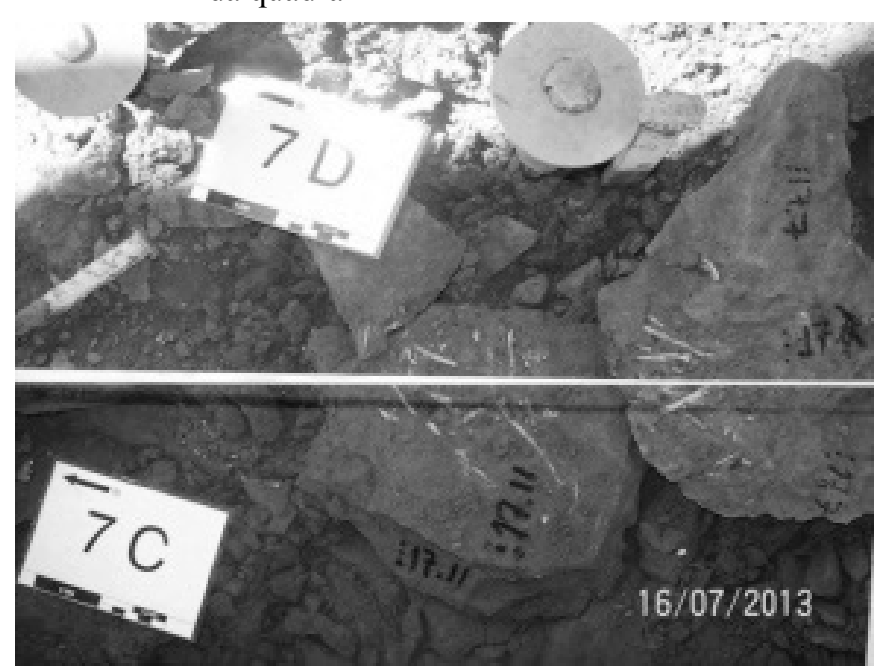

Fonte: Equipe do CENPALEO.

Figura 3 - Blocos para serem embalados e blocos já embalados para transporte, com sua numeração indicativa

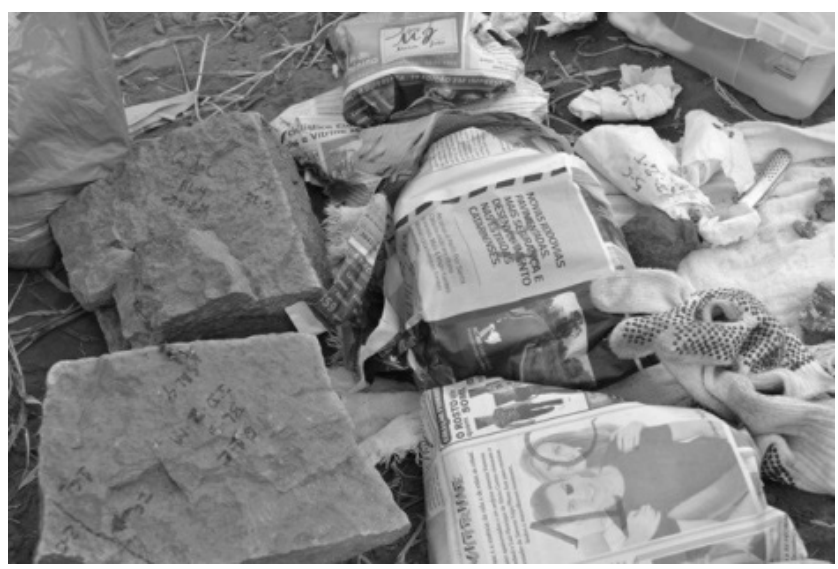

Fonte: Equipe CENPALEO.

\section{Preparação em laboratório}

Depois de coletado e transportado, o material vem sendo devidamente preparado em laboratório. Essa preparação tem como objetivo desagregar mecanicamente o sedimento e expor partes fósseis, retirar impregnações indesejadas e utilização de substâncias para darem resistência ao fóssil exposto no campo. É um trabalho artesanal, que deve ser feito com muita paciência, para não estragar os fósseis.

A preparação pode ser feita de diferentes formas. Neste caso é feita utilizando materiais como agulhas de seringa, formões pequenos, martelos pequenos, alguns equipamentos de uso odontológico, pinças e pincéis. Alguns fósseis, devido ao seu tamanho reduzido, tiveram sua preparação feita com auxílio de estereoscópio. Para preservação e conservação do material, substâncias como acetona e "paraloid" foram administradas. O "paraloid" é uma resina plástica, sólida em temperatura ambiente, é dissolvida em acetona, geralmente em concentração 5 ou $20 \%$. Quando o fóssil é impregnado por acetona, esta elimina pequenas partículas presentes em poros e rachaduras do material; em seguida, quando administrado o "paraloid" em solução com acetona, ele irá preencher estas cavidades, e a acetona logo se volatilizará fazendo com que o paraloide volte ao estado sólido, conferindo proteção ao material.

Para a retirada mecânica do sedimento são utilizados diversos equipamentos, que sensivelmente são lanceados contra a rocha, fazendo com que os grãos do sedimento se soltem, expondo o fóssil totalmente ou parcialmente. É um trabalho que exige paciência, leva tempo. Caso contrário, há chance de danificar ou até mesmo destruir o fóssil, se não tiver paciência e se não fizer o trabalho com cautela.

Para preparar um fóssil, há uma sequência de ações:

- Fotografar a peça;

- Eliminar um pouco de sedimento;

- Aplicar a acetona;

- Aplicar o paraloid.

Figura 4 - Exemplo de peça em preparação. Há muitos ossos que ainda não foram revelados

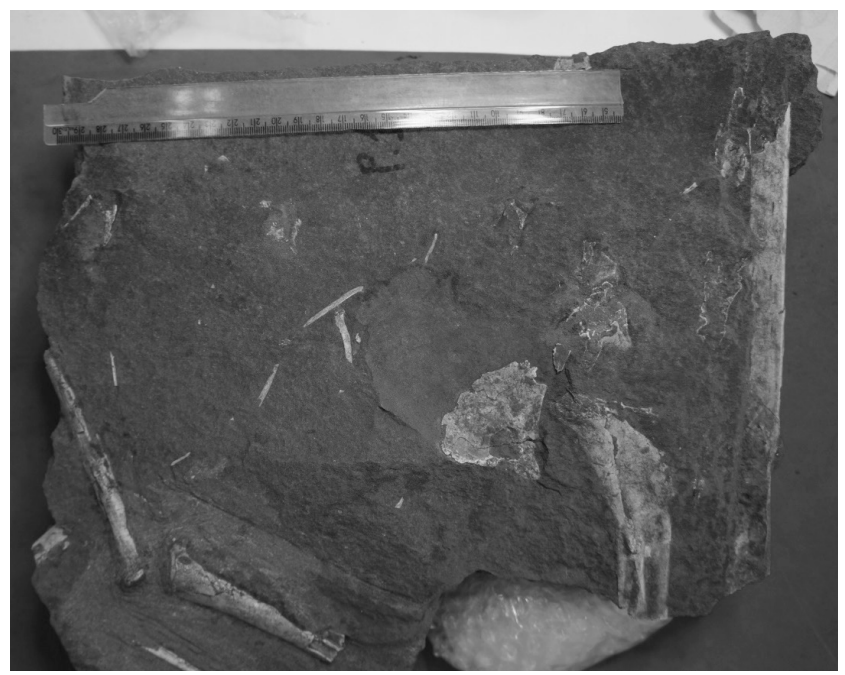

Fonte: Equipe CENPALEO. 
A preparação objetiva a visualização da totalidade do fóssil (quando for possível), facilitando a observação de características distintivas para sua classificação.

Figura 5 - A peça está parcialmente preparada, muitos ossos, antes ocultos, apareceram. Notar a presença de paraloid nos ossos, para preservá-los e protegêlos, dando um aspecto brilhante

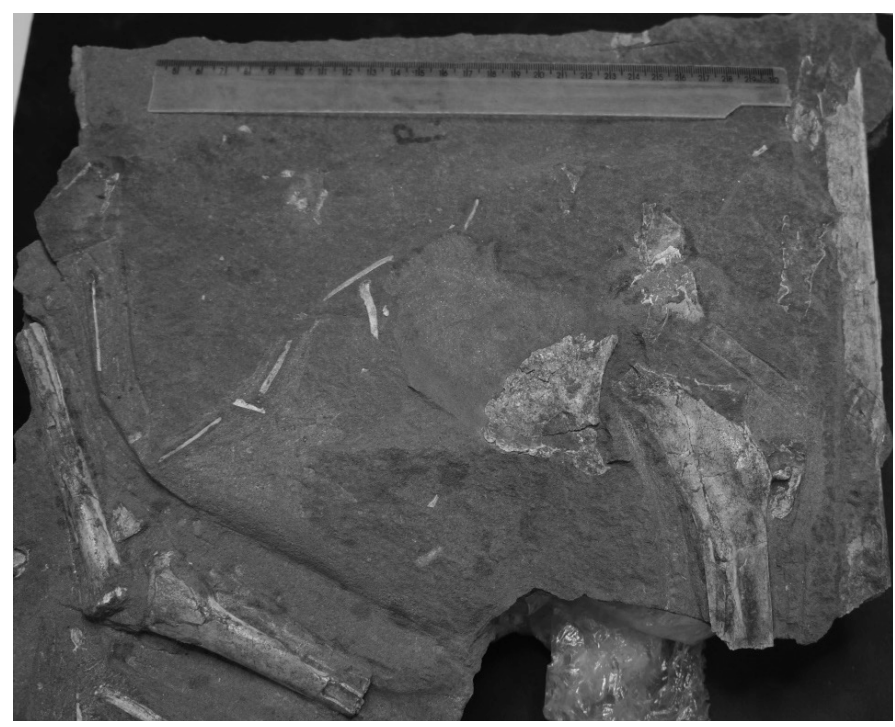

Fonte: Equipe CENPALEO

\section{Identificação}

Os fósseis utilizados para o trabalho são restos de Caiuajara dobruskii (MANZIG et. al., 2014). Os restos sofreram permineralização, processo pelo qual as cavidades naturais dos ossos são preenchidas por cristais, e recristalização, processo pelo qual os cristais formadores sofrem alteração, passando a "crescer", podendo até destruir o fóssil.

\section{Considerações finais}

Os fósseis utilizados para a elaboração deste trabalho encontram-se sob proteção do CENPALEO, possibilitando novos estudos futuros. As técnicas aqui descritas para preparação de fósseis auxiliam na proteção e preservação do patrimônio fossílifero deste.

\section{Referências}

CARVALHO, Ismar de Souza (editor). Paleontologia. Rio de Janeiro: Interciência, 2000.

HICKMAN, Cleveland P.; ROBERTS, Larry S.; LARSON, Allan. Princípios integrados de zoologia. 11. ed. Rio de Janeiro: Guanabara Koogan, 2004.
KELLNER, Alexander W. A. Pterossauros: Os senhores do céu do Brasil. Rio de Janeiro: Vieira \& Lent, 2006.

MANZIG, P.C.; KELLNER, A.W.A.; WEINSCHÜTZ, L.C.; FRAGOSO, C.E.; VEGA, C.S.; GUIMARÃES, G.B.; GODOY, L.C.; LICCARDO, A.; RICETTI, J.H.C.; MOURA, C.C. Discovery of a Rare Pterosaur Bone Bed in a Cretaceous Desert with Insights on Ontogeny and Behavior of Flying Reptiles. PLoS ONE, agosto de 2014.

MANZIG, Paulo César; WEINSCHÜTZ, Luiz, Carlos. Museus e fósseis da Região Sul do Brasil. Marechal Cândido Rondon, PR: Germânica, 2012.

PINHEIRO, Felipe L. Sobre um novo espécime de Tupandactylus Imperator (Archosauria, Pterosauria), proveniente da formação Crato (Eocretáceo) da Bacia do Araripe, Ceará, nordeste do Brasil. 2011. Disponível em: http://www.academicoo.com/ artigo/sobre-um-novoespecime-de-tupandactylus-imperator-archosauria-pterosauria-prove niente-da-formacao-crato-eocretaceo-da-bacia-do-araripe-cearanordeste-do-brasil.

STORER, Tracy I.; USINGER, Robert L.; STEBBINS, Robert C.; NYBAKKEN, James W. Zoologia geral. 6. ed. São Paulo: Nacional, 2003. 